\title{
Equidad de género y formación de oficiales del Ejército Nacional de Colombia: un camino hacia la ética militar ${ }^{1}$
}

https://doi.org/10.21830/9789585377141.04

\author{
Andrés Eduardo Fernández Osorio ${ }^{2}$ \\ Escuela Superior de Guerra "General Rafael Reyes Prieto" \\ Leidy Johana Cabrera Cabrera ${ }^{3}$ \\ Escuela Militar de Cadetes "General José María Córdova” \\ María Antonieta Corcione Nieto ${ }^{4}$ \\ Escuela de Aviación del Ejército \\ Edna Jackeline Latorre Rojas ${ }^{5}$ \\ Centro de Educación Militar
}

\begin{abstract}
1 Este capítulo presenta los resultados colaborativos de dos proyectos de investigación: (1) "Ética militar en entornos complejos de seguridad y defensa: lecturas y aportes desde la experiencia de las Fuerzas Militares de Colombia”, del grupo de investigación Masa Crítica, de la Escuela Superior de Guerra "General Rafael Reyes Prieto", Colombia, categorizado en B por Minciencias y con código de registro COL0123247, y (2) "Mujeres de arma, seguridad y defensa nacional. Un análisis desde sus percepciones", del grupo de investigación en Ciencias Militares, de la Escuela Militar de Cadetes "General José María Córdova”, Colombia, categorizado en B por Minciencias y con código de registro COL0082556. Los puntos de vista pertenecen a los autores y no reflejan necesariamente los de las instituciones participantes.

2 Teniente Coronel del Ejército Nacional de Colombia. PhD en Derecho y Ciencia Política de la Universidad de Barcelona, España. Magíster en Economía, Estado y Sociedad: Política y Seguridad de la University College Londres, Reino Unido. Magíster en Relaciones Internacionales de la Higher School of Economics, Moscú, Federación de Rusia. Investigador del grupo de investigación Centro de Gravedad, de la Escuela Superior de Guerra "General Rafael Reyes Prieto", Colombia. Orcid: https://orcid.org/00000003-0643-0258 - Contacto: andres.fernandez@buzonejercito.mil.co

3 Magíster y especialista en Docencia e Investigación Universitaria de la Universidad Sergio Arboleda. Trabajadora social de la Universidad de La Salle. Investigadora júnior del grupo de investigación en Ciencias Militares de la Escuela Militar de Cadetes “General José María Córdova”, Colombia. Investigadora del grupo de investigación en Aviación Militar. ORCID: http://orcid.org/0000-0002-6398-6933 - Contacto: leidycabreracabrera@cedoc.edu.co

$4 \mathrm{PhD}$ en Antropología de la Universidad de los Andes, Colombia. Magíster en Biología Humana de la Universidad Autónoma de Barcelona y Universidad de Barcelona, España. Antropóloga de la Universidad de los Andes, Colombia. Orcid: https://orcid.org/0000-0002-3509-5519 - Contacto: mariacorcionenieto@cedoc.edu.co

5 Magíster en Educación e Investigación Universitaria de la Universidad Sergio Arboleda. Especialista en Educación e Investigación Universitaria de la Universidad Sergio Arboleda. Psicóloga de la Universidad Católica de Colombia. Docente e investigadora. OrCID: https://orcid.org/0000-0002-03019036 - Contacto: edna.latorre@esmic.edu.co
\end{abstract}




\section{Resumen}

La promoción de la cultura de la equidad de género en el ámbito militar es un proceso que se viene afianzando a partir de diferentes esfuerzos e iniciativas institucionales. Este capítulo analiza las percepciones sobre el fomento de la equidad de género en la Escuela Militar de Cadetes "General José María Córdova" (EsMic) en perspectiva de las capacidades existentes para configurar una estrategia de innovación educativa orientada hacia la ética militar. Para ello, se realizó una revisión documental y un análisis sociodemográfico y de grupos focales con el fin de interpretar las percepciones sobre igualdad de oportunidades, reconocimiento de logros de las mujeres, posibles tratos discriminatorios y esquemas de desventaja profesional. Con este balance, se busca fortalecer los espacios ya ganados para la equidad de género, identificar las áreas susceptibles de mejora y sugerir nuevos escenarios de participación desde un enfoque ético militar.

Palabras clave: Escuela Militar de Cadetes; equidad de género; ética militar; innovación educativa; mujer militar.

\section{Introducción}

La equidad de género es uno de los temas más discutidos durante las últimas décadas en el mundo por decisores políticos, académicos, defensores de Derechos Humanos y la sociedad en general. El justo reconocimiento del valor de las personas y la posibilidad de materializar los sueńos y el plan de vida individual es fundamental para la consolidación de la democracia y el mantenimiento del Estado social de derecho.

Sin embargo, en América Latina y el Caribe este debate ha tenido una evolución menos dinámica en razón de algunas tradiciones culturales y particularidades sociales sobre los desarrollos, representaciones e identidades de género arraigadas en la región. En efecto, una importante cantidad de estudios —como los de McIlwaine (2010), Pardo et al. (2013), Daros (2014), Barredo et al. (2014), Felitti y Rizzotti (2016), Eggleton (2018), Cone (2018), Rojas (2018) y Knippers (2018) — ha demostrado el impacto negativo de costumbres y prácticas sexistas frecuentes en la sociedad y familias latinoamericanas para la construcción de una cultura de equidad sin distinciones de género.

Estas costumbres sociales y familiares impactan en diferentes aspectos sociales (Rey, 2021) que se pueden clasificar en cuatro grupos principales. 
Primero, la falta de igualdad en oportunidades de desarrollo personal — tema que ha sido estudiado por Ariza y De Oliveira (1999), Abramo (2006), Reyes (2012), Suárez et al. (2015) y Muñoz e Iniesta (2017), entre otros-. Segundo, la diferencia en el reconocimiento de logros —explorado por académicos como Montoya (2009), Londońo et al. (2017), Vargas (2016) y Meertens (2017)—. Tercero, el trato discriminatorio —analizado por Guarnizo-Herreño y Agudelo (2008), Otero e Ibarra (2017), Avelar et al. (2018) y Arroyo y Álvarez (2018) — , y cuarto, las desventajas profesionales — investigado por Chant et al. (2007), Galvis-Aponte (2010), Camacho (2013) y González et al. (2014).

La Escuela Militar de Cadetes "General José María Córdova” (Esmic), centro de formación de los futuros oficiales del Ejército Nacional de Colombia, tiene carácter de institución de educación superior (IEs) y, a través de un programa académico de cuatro años, forma a los hombres y las mujeres encargados de liderar las unidades de la Fuerza y ejercer la defensa de "la soberanía, la independencia, la integridad del territorio nacional y del orden constitucional" (Constitución Política de Colombia, 1991, art. 217). Esta tarea no desconoce el desafío que representa el desarrollo de estrategias educativas innovadoras para el fomento de la equidad de género en la búsqueda de optimizar la formación ética de nuevos cadetes acorde con las necesidades actuales de los escenarios globales.

La innovación puede definirse como la selección, organización y utilización creativa de recursos humanos y materiales de maneras nuevas y propias que den como resultado la conquista de un nivel más alto con respecto a las metas y los objetivos previamente marcados (Richland; citado por Moreno, 1995). En el caso de la innovación educativa, estas innovaciones tienen que ser evaluadas y solo pueden valorarse en relación con las metas y los objetivos de un determinado sistema educativo, no son transferibles de un sistema a otro, lo que determina su carácter intrínseco y transversal a los macro, meso y microcurrículos de una institución de educación. Así, la innovación auténtica requiere ser duradera, tener un alto índice de utilización y estar relacionada con mejoras sustanciales de la práctica educativa (Organización de Estados Iberoamericanos [Oei], s.f.).

Siendo así, la innovación educativa vincula cuatro ámbitos. El primero sugiere la configuración de nuevas áreas o contenidos curriculares. La utiliza- 
ción de nuevos materiales y tecnologías curriculares. La aplicación de nuevos enfoques y estrategias de los procesos de enseñanza y aprendizaje, así como el cambio de las creencias y los presupuestos pedagógicos de los diferentes actores educativos (Macías, 2005). Evidentemente, las innovaciones educativas tienen el poder de transformar positivamente las culturas y son numerosos los ejemplos que pueden encontrarse en la literatura al respecto (por ejemplo, Gómez, 2005). La perspectiva cultural considera que toda innovación tiene que hacer frente a una interacción cultural, a un choque entre culturas y subculturas (Olson, 1992). La innovación representa un conjunto de significados y valores culturales propios y compartidos (García \& Martija, 2006).

De esta forma, es importante abrir el espacio de comprensión para el concepto de cultura. En un sentido amplio, la cultura se refiere al comportamiento aprendido o a los patrones de vida predominantes, mientras que, en un sentido específico, la cultura se considera como un sistema de valores y sensaciones de la sociedad (Cota, 2002). En la cultura de igualdad y equidad de género se constata una opinión pública más favorable a la participación equitativa de las mujeres y una mayor aceptación de la igualdad entre hombres y mujeres a pesar de la persistencia cultural de asignaciones de roles estereotipados entre sexos. Por el contrario, la cultura patriarcal es un fuerte obstáculo al avance del liderazgo y la representatividad femenina (Plan Nacional de Igualdad y Equidad de Género [Planeg], s. f.).

El concepto de innovación educativa y su efecto sobre la cultura lleva a un tercer concepto: la ética, que junto con la educación y la cultura constituyen elementos que se vinculan en el proceso para que los individuos sean merecedores de la felicidad a partir del buen uso de la libertad (Leal \& Useche, 2009). La ética es la reflexión del propio modelo de vida, en donde la razón tiene un papel importante en la toma de decisiones para comprender, justificar y argumentar, lo que vincula también a los derechos y los deberes (Betancur, 2016). Consecuentemente, la ética es una ciencia útil en el camino para determinar un cambio cultural, lo que es especialmente deseable a nivel institucional y en referencia a un tema de tan alta relevancia como la equidad de género.

Para una institución como el Ejército Nacional, el concepto ética debe trascender al de cultura organizacional ética, que es definida como aquella cuyos artefactos, mitos, valores e ideología contienen en su núcleo una reflexión 
sobre lo correcto e incorrecto de los comportamientos dentro y alrededor de la organización, lo cual depende del liderazgo de la dirección y se apoya, formal e informalmente, en la estrategia y estructura de la organización (Rodríguez, 2015). Así, los comportamientos en los miembros del Ejército Nacional deben sustentarse no solo en documentos de valor declarativo, sino también en sistemas de capacitación eficaces en el conocimiento y la interiorización de la ética militar, poniendo especial interés a los cambios en los principios y valores sociales y culturales, tanto de su propia sociedad como del resto de países del actual mundo interconectado y globalizado (Moliner, 2018). Como cimiento, las instituciones educativas como la EsMic tienen una gran responsabilidad en cambiar esas tradiciones culturales y contribuir a la eliminación de las prácticas discriminatorias a través de estrategias educativas innovadoras orientadas hacia la ética militar.

Aun así, este tema no ha sido explorado en todas sus dimensiones y la producción bibliográfica es bastante discreta. En especial, el estudio, la formulación y la evaluación de estrategias de innovación educativa para el fomento de la equidad de género han estado ausentes del debate académico militar. Si bien investigaciones recientes como las de Alcívar y Cedeño (2012), Ronconi (2018), Ruiz-Gutiérrez y Santana-Vega (2018), Castillo-Acobo y ChoqqueSoto (2018), Weiss \& Rey (2020), González-González et al. (2018) y Otálvaro et al. (2018) han aportado a la comprensión de los retos y las complejidades de la equidad de género en la educación superior, aún faltan mayores esfuerzos para consolidar las didácticas y estrategias orientadas a la innovación educativa en este sentido.

Frente a este panorama, el presente capítulo busca analizar las percepciones sobre el fomento de la equidad de género en la Esmic en perspectiva de las capacidades existentes para configurar una estrategia de innovación educativa orientada hacia la ética militar.

\section{Metodología}

Este capítulo se configuró como un estudio de tipo mixto que incluyó una revisión documental sobre categorías asociadas con igualdad, equidad, innovación educativa y ética militar; así mismo, abordó como base de análisis 
el estudio sociodemográfico de la Esmic realizado por Fernández-Osorio et al. (2018), en el cual se empleó una encuesta voluntaria y anónima de 150 preguntas de opción múltiple para examinar las percepciones de los estudiantes en seis áreas: (1) características sociodemográficas, (2) comportamiento profesional, (3) patrones sociales, (4) valores militares, (5) relaciones entre civiles y militares y (6) integración de la mujer en el Ejército.

El estudio se realizó en mayo de 2018, cuando la población total de la Esmic era de 1.105 hombres (79\%) y 297 mujeres (21 \%). La mayoría de las preguntas se estructuraron en una escala tipo Likert de 5 puntos, con algunas excepciones, por ejemplo, la edad y el departamento de origen. Las respuestas se recolectaron utilizando un formulario de reconocimiento óptico (OMR) y fueron corroboradas manualmente por tres investigadores para evitar errores técnicos.

Todos los encuestados fueron informados de los objetivos y el alcance del estudio; cada uno firmó un consentimiento informado que autoriza el uso de los datos recopilados con fines académicos. El estudio se validó a través de una revisión por pares en sistema doble-ciego y fue aprobado por el Comité de Ética en Ciencias Sociales y Exactas (Cecse) de la Esmic.

En total, el estudio recolectó las respuestas de 1.120 voluntarios (lo equivalente al 80 \% de la población total de la Esmic), distribuidos en ocho niveles académicos (el primer ańo de estudios, comprendido por el primer y segundo nivel académico; el segundo ańo, tercer y cuarto nivel académico; el tercer año, quinto y sexto nivel académico, y el cuarto año, séptimo y octavo nivel académico).

De los 1.120 encuestados, aproximadamente el $79 \%$ eran hombres (n $=886)$ y el $21 \%$ mujeres $(n=234)$. Todos los encuestados eran graduados de secundaria, tenían la calidad de estudiantes de la Esmic y cursaban el programa educativo y de entrenamiento de futuros oficiales del Ejército Nacional de Colombia, que, al término de cuatro años, les otorga un título universitario en ciencias militares y un título universitario en relaciones internacionales, derecho, administración logística, entrenamiento físico o ingeniería civil.

\section{Variables}

Del universo de preguntas se seleccionaron seis para este estudio, las cuales permiten evaluar el nivel de equidad de género y de igualdad de oportu- 
nidades en la Esmic, a través de cinco variables: (1) el nivel académico cursado en la Esmic, (2) el reconocimiento de logros, (3) los posibles tratos discriminatorios, (4) las potenciales desventajas profesionales en relación con el género y (5) la transformación del Ejército para la aceptación de mujeres en sus filas.

Analizadas de forma grupal (tabla 1), las variables representan el $62,9 \%$ de la variación en la mejora de la igualdad en la EsMic (R2 = 0,629). La regresión es estadísticamente significativa, $\alpha=0,05 ; \mathrm{F}(4,1115)=0,000, \mathrm{p}<$ 0,05, lo cual significa que existe una posible correlación de todo el modelo con el nivel de equidad en la Esmic.

Las variables "nivel académico (semestre) en la Esmic" ( $p=0,00<0,05)$, "eliminación del posible trato discriminatorio" ( $\mathrm{p}=0,00<0,05)$ y "eliminación de desventajas ante los hombres" ( $\mathrm{p}=0,00<0,05)$ son estadísticamente significativas. En otras palabras, las estrategias educativas relacionadas con el semestre académico que adelantan los estudiantes y que buscan eliminar el posible trato discriminatorio y las desventajas de las mujeres ante los hombres incrementan la posibilidad de que se obtenga un ambiente de igualdad entre compańeros.

\section{Grupos focales}

Los resultados del cuestionario anterior se complementaron con un ejercicio de grupos focales en el que participaron 164 estudiantes (hombres y mujeres), correspondientes al 11,7 \% de la totalidad de la población de la Esmic. La muestra poblacional se seleccionó de forma aleatoria y voluntaria, con una composición de $50 \%$ hombres y $50 \%$ mujeres, correspondientes por lo menos al $10 \%$ de cada uno de los ocho niveles académicos.

El objetivo del grupo focal fue identificar la información asociada a los conocimientos, actitudes, creencias, sentimientos y experiencias frente a la equidad de hombres y mujeres en la EsMic, a través de la realización de entrevistas semiestructuradas en la población de estudio. Las sesiones tuvieron un promedio mixto de 15 participantes en un tiempo de una hora, lapso en el que se exploraron las variables analíticas que se muestran en la tabla 2. 


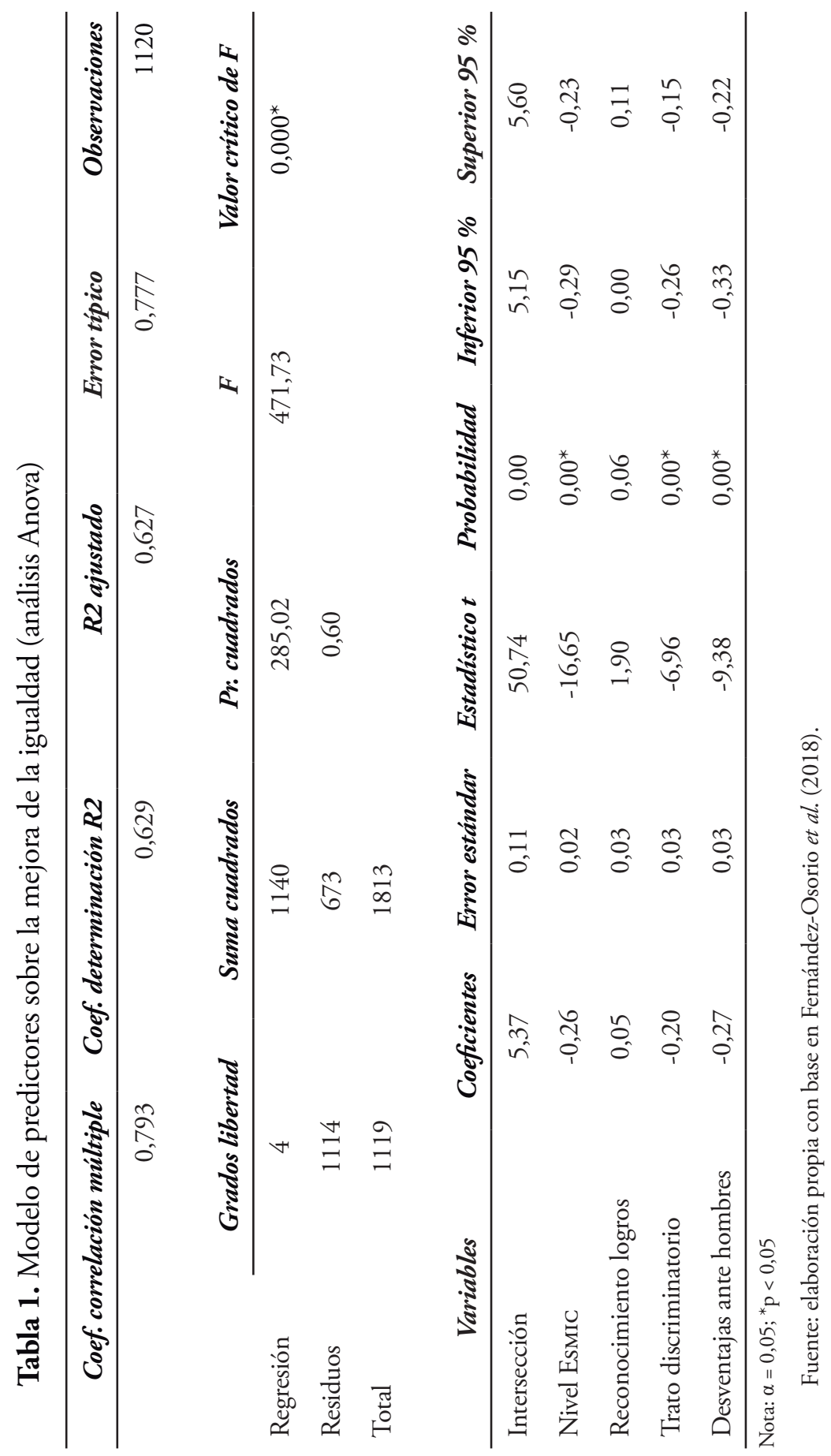


Tabla 2. Variables utilizadas en los grupos focales realizados en la Esmic

\begin{tabular}{|c|c|}
\hline Variables analíticas & Indicadores \\
\hline $\begin{array}{l}\text { Demográficas } \\
\text { Características estadísticas básicas de la pobla- } \\
\text { ción. }\end{array}$ & $\begin{array}{l}\text { Edad, ciudad de procedencia, cantidad de } \\
\text { hermanos, estado civil, estado civil de los } \\
\text { padres, sexo. }\end{array}$ \\
\hline $\begin{array}{l}\text { Macrosistema } \\
\text { Contextos culturales, valores, creencias y } \\
\text { representaciones culturales de la equidad entre } \\
\text { hombres y mujeres en la sociedad colombiana } \\
\text { y en la EsMic. }\end{array}$ & $\begin{array}{l}\text { Definición de la masculinidad como domi- } \\
\text { nación y dureza; definición de la feminidad } \\
\text { como sumisión y debilidad; mantenimiento } \\
\text { del honor masculino; profundización de los } \\
\text { roles de género. }\end{array}$ \\
\hline $\begin{array}{l}\text { Exosistema } \\
\text { Comunidad y factores económicos; factores } \\
\text { estructurales que afectan la legitimación social } \\
\text { de los roles del hombre y la mujer en lo acadé- } \\
\text { mico, la familia, los medios de comunicación, } \\
\text { los pares, las justicia y los contextos socioeco- } \\
\text { nómicos en el Ejército Nacional de Colombia. }\end{array}$ & $\begin{array}{l}\text { Separación del espacio público y privado; } \\
\text { fortalecimiento de la identidad masculina con } \\
\text { los pares; reconocimiento o invisibilización de } \\
\text { la identidad femenina. }\end{array}$ \\
\hline $\begin{array}{l}\text { Microsistema } \\
\text { Relaciones interpersonales; entornos inme- } \\
\text { diatos. }\end{array}$ & $\begin{array}{l}\text { Ordenamiento patriarcal de las familias; inte- } \\
\text { racción entre pares; relaciones afectivas. }\end{array}$ \\
\hline $\begin{array}{l}\text { Endosistema } \\
\text { Procesos de aprendizaje individual y normali- } \\
\text { zación de los roles mujer/hombre en la forma- } \\
\text { ción de la Esmic. }\end{array}$ & $\begin{array}{l}\text { Formación académica; formación práctica; } \\
\text { formación desde el ser (para pensar). }\end{array}$ \\
\hline
\end{tabular}

Fuente: elaboración propia.

\section{Resultados y discusión}

\section{Igualdad de oportunidades}

La igualdad de oportunidades para hombres y mujeres resulta ser un aspecto esencial en los procesos educativos de las instituciones, pues es a partir de un trato igualitario que se garantiza un proceso de formación que incluya a las mujeres militares dentro de un medio que por años se ha configurado como masculino, como es el caso de la Esmic y en general del Ejército Nacional.

Un aspecto importante a tener en cuenta es la progresión de la percepción de la igualdad de oportunidades en los estudiantes de la Esmic (figura 1). Se evidencia que hombres y mujeres ingresan a la Esmic con una gran carga de 
estereotipos, reflejados en las percepciones del nivel académico I, en las cuales el $100 \%$ de las mujeres y de los hombres consideran que "nunca", "rara vez" o "algunas veces" hay igualdad de oportunidades para hombres y mujeres en el Ejército Nacional de Colombia. Esta percepción se mantiene en el nivel académico II, en el que el $100 \%$ de las mujeres y el $89 \%$ de los hombres siguen afirmando que "nunca", "rara vez" o "algunas veces" hay igualdad de oportunidades en el Ejército Nacional.

P1: ¿Cree usted que hay igualdad de oportunidades para hombres y mujeres en el Ejército Nacional de Colombia?

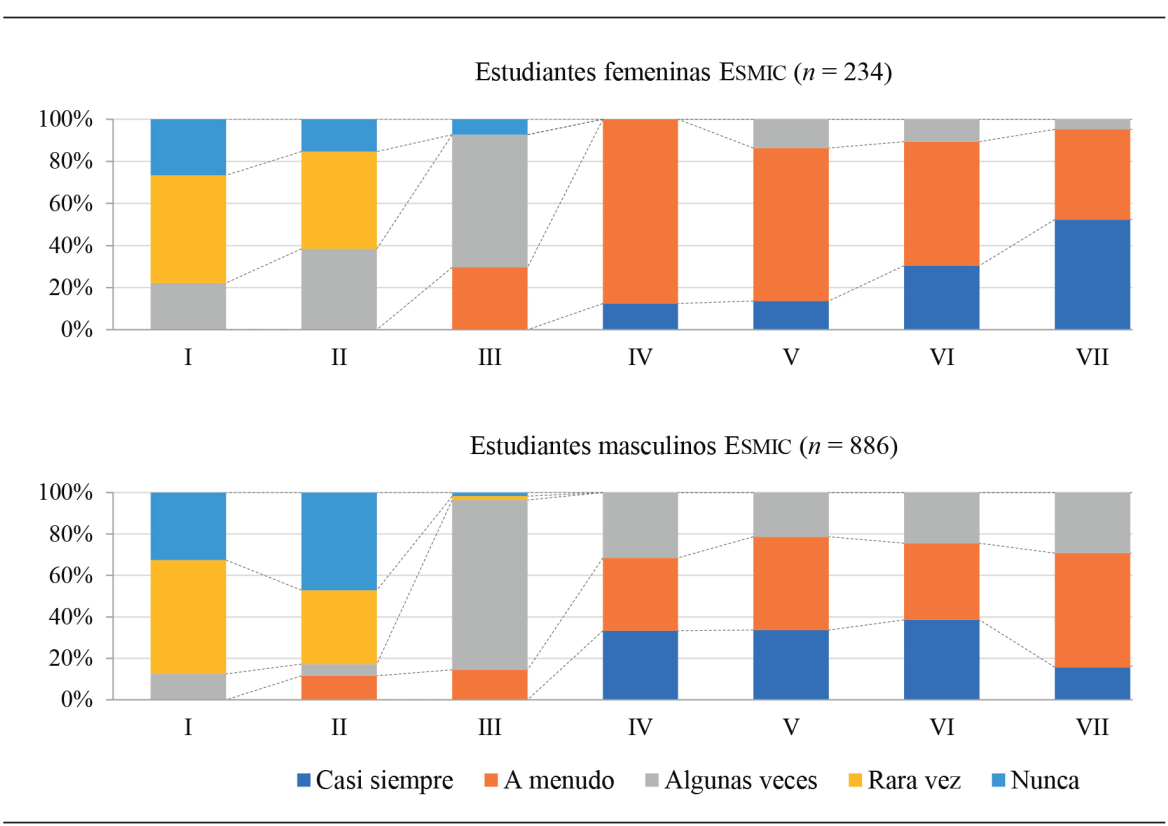

Figura 1. Progresión por semestre (I-VIII) en la percepción de igualdad de oportunidades en los estudiantes de la Esmic $(n=1.120)$.

Fuente: elaboración propia con base en Fernández-Osorio et al. (2018).

No obstante, a partir del tercer nivel se nota una mejora significativa, pues el "nunca" y el "rara vez" desaparecen y se evidencia un aumento hacia el "a menudo" y "casi siempre", dado que los estudiantes comprenden que las oportunidades de desarrollo de su carrera profesional tienen igualdad de condiciones tanto para hombres como para mujeres dentro del Ejército Nacional. 
En el tercer y cuarto nivel se evidencia en las mujeres un gran aumento de la percepción de igualdad, en razón a que en estos dos niveles tienen la posibilidad de mando sobre sus compañeros según sus resultados académicos y militares. Esta tendencia se mantiene en quinto y sexto semestre, hasta que, en el octavo semestre, se alcanzan niveles de "algunas veces" en el $10 \%$ de las mujeres y el $28 \%$ de los hombres.

\section{Reconocimiento de los logros de la mujer}

Al igual que en la variable "igualdad de oportunidades", la percepción sobre el "reconocimiento de los logros de la mujer" muestra una tendencia de los estudiantes a ingresar con una carga de prejuicios a la Esmic que va siendo mitigada a lo largo de los ocho niveles de formación académica y militar. Algo particular es que las mujeres que ingresan tienen una mejor percepción (29 \% de "algunas veces") que los hombres (100\% de "nunca" o "rara vez") sobre el panorama que vivirán en la Esmic. No obstante, en el quinto y sexto nivel estas percepciones decrecen en las estudiantes femeninas, razón por la cual, esta variable no es estadísticamente significativa $(\mathrm{p}=0,06>0,05)$ (figura 2$)$.

P2: ¿Cree usted que las mujeres son reconocidas por sus logros en el Ejército Nacional de Colombia?

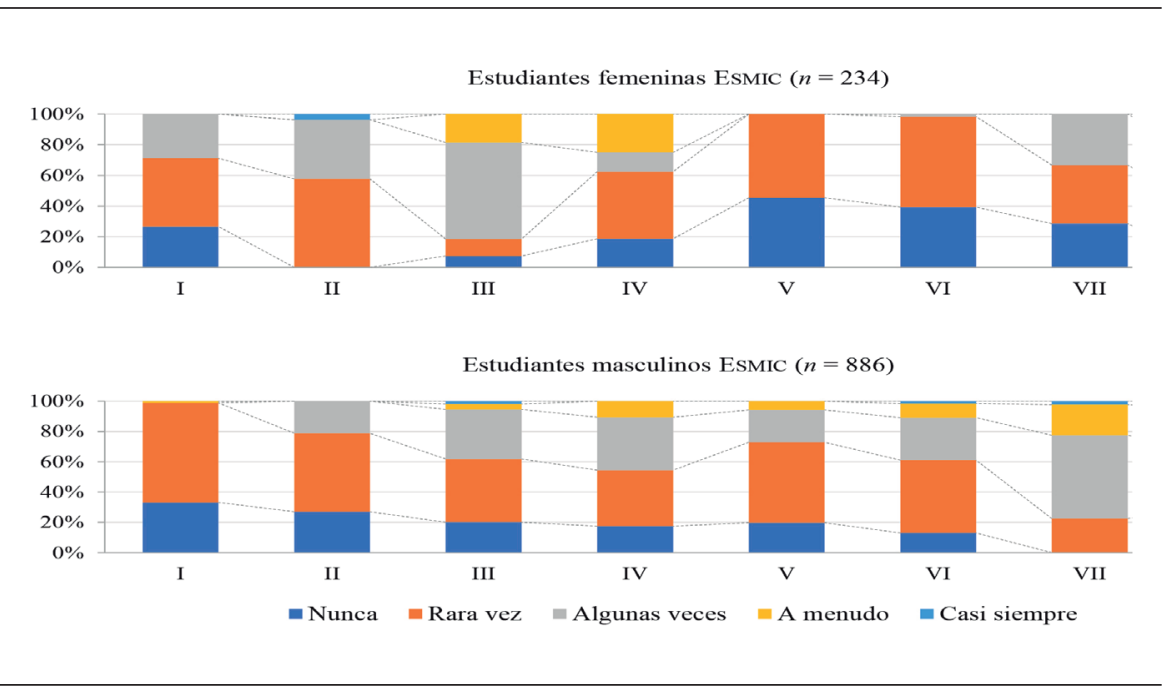

Figura 2. Progresión por semestre (I-VIII) en la percepción sobre el reconocimiento de los logros de la mujer en los estudiantes de la Esmic $(n=1.120)$.

Fuente: elaboración propia con base en Fernández-Osorio et al. (2018). 
Una posible explicación de esta variación, que se acerca nuevamente a mejores niveles en el séptimo y octavo semestre, surge de comparar estos resultados con los del posible trato discriminatorio con las mujeres (figura 3). Las mujeres en esos semestres perciben que "rara vez" o "nunca" habrá lugar a una posible discriminación por cuestión de género. De hecho, los bajos niveles de reconocimiento de sus logros solo se da como producto de la difícil competencia entre mujeres por el gran rendimiento académico y militar que ellas registran como estudiantes en la EsMic. Al ser las mujeres menos de la cuarta parte de la población estudiantil de la Esmic y no recibir tratamiento especial en razón de su género, deben esforzarse continuamente para sobresalir, lo cual da lugar a obvias frustraciones en relación con los resultados deseados por ellas mismas.

Los hombres, a diferencia de las mujeres, tienden a percibir que los logros de ellas son reconocidos en el Ejército Nacional con porcentajes que oscilan entre el $12 \%$ y el $27 \%$ más, respecto de lo que perciben las mujeres en la progresión por semestres.

\section{Trato discriminatorio de la mujer}

A partir del cuarto semestre y hasta séptimo semestre, la población de mujeres encuestadas $(n=234)$ indica que "rara vez" y "nunca" ocurre este tipo de trato (los porcentajes varían entre el $20 \%$ y el $97 \%$ ). En contraste, los hombres comienzan a percibir que el trato no es discriminatorio un poco antes. En tercer semestre, los hombres arrojan un resultado del $82 \%$ en la respuesta "rara vez", en cuanto a percibir un trato discriminatorio hacia la mujer, tendencia que se mantiene en cuarto, quinto y sexto semestre. Sin embargo, estos resultados comienzan a disminuir en séptimo y octavo semestre con el $40 \%$ y el $29 \%$, respectivamente, y son reemplazados por "nunca" y "algunas veces" (figura 3). 
P3: ¿Cree usted que hay algún tipo de trato discriminatorio entre hombres y mujeres en el Ejército Nacional de Colombia?

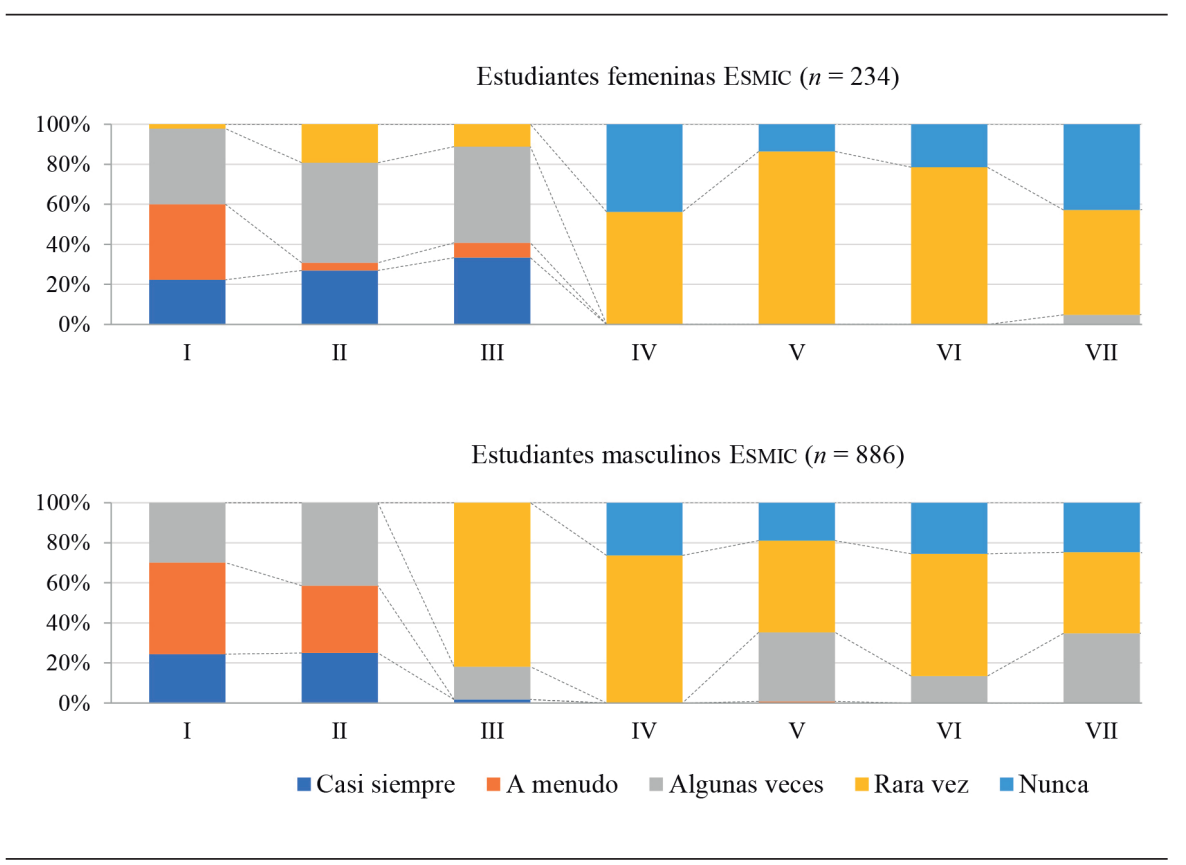

Figura 3. Progresión por semestre (I-VIII) en la percepción sobre trato discriminatorio entre hombres y mujeres en los estudiantes de la Esmic $(n=1.120)$.

Fuente: elaboración propia con base en Fernández-Osorio et al. (2018).

Ahora bien, entre los hombres y las mujeres se incrementa el "algunas veces” en el séptimo y octavo semestre $(35 \%$ y $36 \%$ versus $3 \%$ y $19 \%$, respectivamente). Probablemente, procesos como la selección del arma, sobre la que se estructura su plan de estudios, futuros traslados y carrera militar tienen influencia sobre esta percepción.

Esta selección se realiza de forma pública, cuando los estudiantes cursan el sexto nivel, y se basa en el orden estricto de precedencia de los resultados académicos y militares de los estudiantes (la llamada "antigüedad”) y las necesidades del Ejército. Con un mes de anterioridad, los estudiantes realizan una preselección de las tres armas de su predilección, las cuales son validadas en relación con su aptitud psicofísica. 
Posteriormente, son convocados a una ceremonia militar presidida por el director de la Esmic, en la cual se informa la cantidad de cupos requeridos por el Ejército en cada una de las armas y se les pregunta uno a uno y en orden de antigüedad qué arma eligen. Los estudiantes (hombres y mujeres) pueden acceder, entonces, al arma que hayan seleccionado con base en tres variables: (1) su aptitud psicofísica, (2) su antigüedad y (3) la disponibilidad de cupos en el arma; sin embargo, debido a la necesidad de abrir espacios de participación, en todas las armas se asignan cupos fijos para las mujeres.

Esto significa que se reduce la posibilidad para una cierta cantidad de hombres de seleccionar el arma de su predilección, aun a pesar de ser más "antiguos" que algunas mujeres. Esta situación es percibida en ocasiones como discriminatoria por parte de ellos, sin embargo, se considera necesario para avanzar en la construcción de los roles de las mujeres militares en el Ejército Nacional.

Otro aspecto de debate en cuanto a la escogencia de las especialidades es la posibilidad de que las mujeres puedan seleccionar el arma de infantería y, por consiguiente, participar en misiones de combate. Hasta el año 2017 esto no era permitido, lo cual era motivo de percepciones de discriminación por parte de ellas frente a los hombres. Sin embargo, esta situación cambió a raíz de la consolidación de las políticas de equidad en el Ejército Nacional, de acuerdo con las cuales, a partir de entonces, se les permitió pertenecer a cualquier arma.

\section{Desventajas profesionales de la mujer militar}

La percepción de las desventajas profesionales de la mujer militar por parte de los y las estudiantes se muestra en la figura 4. La progresión, para el caso de mujeres y hombres, indica que, a partir del tercer nivel de formación, se percibe que las desventajas en la obtención de logros profesionales "rara vez" o "nunca" ocurren. En el séptimo semestre, el $35 \%$ de los hombres perciben que algunas veces hay desventajas, mientras que en el octavo semestre tanto hombres como mujeres comienzan a percibir desventajas profesionales de la mujer, con el $33 \%$ y el $25 \%$, respectivamente. 
P4: ¿Cree usted que las mujeres en el Ejército Nacional de Colombia tienen desventajas con respecto a los hombres para la obtención de logros profesionales?

Estudiantes femeninas EsMIC $(n=234)$

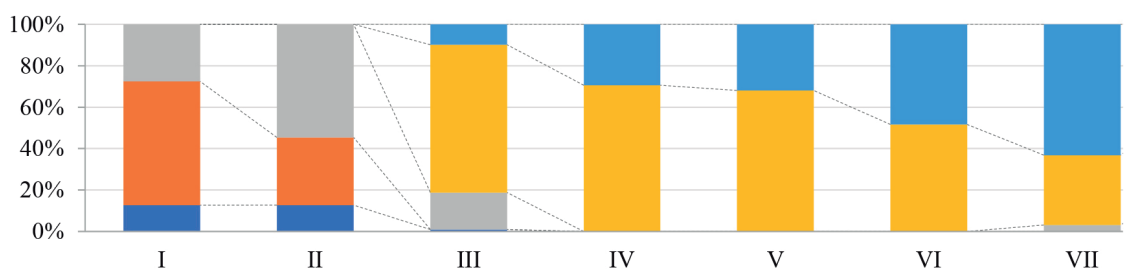

Estudiantes masculinos ESMIC $(n=886)$

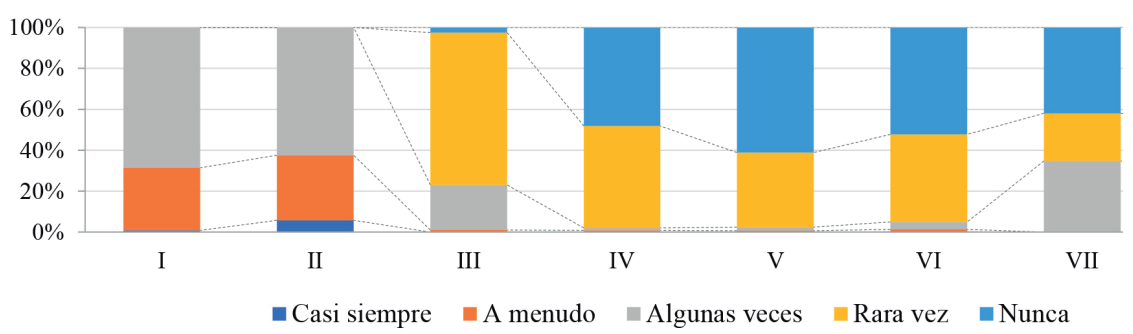

Figura 4. Progresión por semestre (I-VIII) en la percepción sobre desventajas profesionales de las mujeres militares en los estudiantes de la Esmic $(n=1.120)$.

Fuente: elaboración propia con base en Fernández-Osorio et al. (2018).

La percepción en séptimo y octavo semestre puede estar también relacionada con dinámicas institucionales como la mencionada previamente en relación con la escogencia de arma, por cuanto el Ejército se basa en ella para planear los traslados y planes de carrera. Así las cosas, si un oficial (hombre o mujer) no ha podido acceder al arma de su predilección, no podrá tener todas las destinaciones deseadas, de forma que su futuro profesional deberá ser ajustado. Esto puede ser interpretado como desventaja profesional, en especial, por parte de las mujeres que desean continuamente tener una mayor participación en misiones de combate. 


\section{Discusión}

Los movimientos sociales respecto a la participación de las mujeres de manera equitativa en todas las actividades de la sociedad comenzaron a cobrar importancia en la región desde los movimientos feministas, que ponen sobre la mesa estudios, diálogos y discusiones en torno a fenómenos como la desigualdad y la discriminación basada en género. Su finalidad principal fue que estos fenómenos se expresaran en acuerdos internacionales de regulación — tales como la Conferencia Mundial de los Derechos Humanos, la Convención sobre la Eliminación de Todas las Formas de Discriminación contra la Mujer y la Cuarta Conferencia Mundial sobre la Mujer de Beijingy se generaran plataformas de acción. Estos eventos internacionales se convirtieron en mecanismos por los cuales los países latinoamericanos emprendieron acciones y se pusieron metas encaminadas a la construcción de una sociedad más democrática y justa.

Es así como la instauración de una cultura de igualdad entre hombres y mujeres se convirtió en una responsabilidad social y política de los países, para lo cual actualmente se contemplan, según Astelarra (2005, p. 7), tres tipos de políticas: "De igualdad ante la ley, de acción positiva y de transversalización de

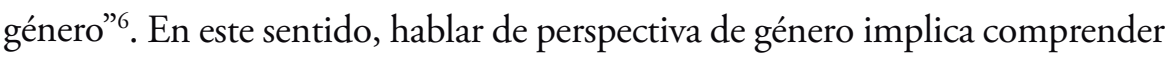
la diferencia sexual y los roles sociales que se construyen a partir de dicha diferencia, con un enfoque homogeneizador (Miranda-Novoa, 2012). De igual forma, el enfoque de género le abre las puertas a la disolución de la diferencia, que resulta importante para establecer políticas públicas con el fin de incorporar a la mujer en roles que habían sido dominados por los hombres, como es el caso de la institución castrense.

6 El Consejo Económico y Social de las Naciones Unidas (Ecosoc) definió el concepto de la transversalización de la perspectiva de género en los siguientes términos: "Transversalizar la perspectiva de género es el proceso de valorar las implicaciones que tiene para los hombres y para las mujeres cualquier acción que se planifique, ya se trate de legislación, políticas o programas, en todas las áreas y en todos los niveles. Es una estrategia para conseguir que las preocupaciones y las experiencias de las mujeres, al igual que las de los hombres, sean parte integrante en la elaboración, puesta en marcha, control y evaluación de las políticas y de los programas en todas las esferas políticas, económicas y sociales, de manera que las mujeres y los hombres puedan beneficiarse de ellos igualmente y no se perpetúe la desigualdad. El objetivo final de la integración es conseguir la igualdad de los géneros" (CEPAL, 2019). 
Claramente, Colombia no es ajena a las demandas mundiales respecto a las condiciones de equidad e igualdad, por lo cual ha asumido los retos de incorporar en sus políticas públicas los elementos jurídicos requeridos para aumentar la igualdad y disminuir las violencias entre hombres y mujeres, tales como el Modelo Ecológico Feminista Integrado. Este es tomado del Fondo de Desarrollo de las Naciones Unidas para la Mujer (Unifem), el Fondo de Población de las Naciones Unidas (UnfPA), la Organización Internacional para las Migraciones (Оıм), el Fondo de las Naciones Unidas, el Gobierno de España para el Cumplimiento de los Objetivos de Desarrollo del Milenio (MDGF) y la Consejería Presidencial para la Equidad de la Mujer. Este modelo se ha constituido en un hito para los paradigmas de interpretación de la violencia contra las mujeres, por lo cual se ha tomado como punto de partida en estos aspectos en el país.

El modelo, propuesto por Lori Heise (1998), plantea la aplicación de un esquema ecológico al conocimiento de las violencias contra las mujeres. Se basa en el reconocimiento de las violencias contra las mujeres como un fenómeno dinámico que se produce en la interacción de las historias individuales, las relaciones más inmediatas (microsistema), los ámbitos socioeconómicos donde se producen (ecosistema) y los contextos culturales (microsistemas).

De acuerdo con Heise (1998), el enfoque sintetiza los hallazgos comprobados por investigaciones empíricas con elementos innovadores para dar cuenta de las diferentes expresiones de las violencias contra las mujeres. Tal enfoque ha sido utilizado en otras investigaciones, como el Informe mundial sobre violencia y salud de la OMS (2002) y el Estudio multipaís de la OMS sobre salud de la mujer y violencia doméstica contra la mujer (OMs, 2013).

Aproximaciones teóricas como las anteriores llevan a entender que, cuando se habla de equidad de género, se hace referencia a "la justicia necesaria para ofrecer el acceso y el control de recursos a mujeres y hombres por parte del gobierno, de las instituciones educativas y de la sociedad en su conjunto" (Apún, 2019, s. p.). Así mismo, permiten entender que la igualdad de género, hoy en día, es catalogada como un derecho fundamental y un principio jurídico universal: según las Naciones Unidas, la igualdad de género se refiere a la igualdad de derechos, responsabilidades y oportunidades de hombres, mujeres, 
niñas y niños, por lo cual se entiende que el sexo con el que se haya nacido no es discriminatorio para contar o no con un derecho.

Y aunque en la actualidad hay más mujeres entre los estudiantes de educación superior en la mayoría de países (Ordorika, 2015), aún a lo largo del mundo es mayor la discriminación que viven las mujeres y las niñas por el simple hecho de haber nacido mujeres. Por ello, una de las propuestas de los Objetivos de Desarrollo Sostenible para el 2030 (Onu, 2016) es lograr la igualdad entre los géneros y empoderar de sus derechos a todas las mujeres y las nińas, de acuerdo con lo plasmado en el informe Perseguir la igualdad de género: una batalla cuesta arriba (OECD, 2017).

\section{Construcción de una cultura de equidad y ética militar a través de la innovación educativa}

Se entiende por cultura de género aquellos elementos que determinan la manera de interpretar la distinción masculino-femenino, y que se manifiestan en dos planos (Crawford, 2006; citado por Piquer, 2012):

- El género como un proceso dinámico de representación de lo que significa ser hombre o mujer. Esto se va construyendo a partir del transcurso de las situaciones de la vida diaria. Así, los papeles, los discursos y las prácticas relacionadas con el género determinan los procesos de socialización que vamos viviendo y ponen las bases sobre las cuales creamos modelos y relaciones de género.

- El género como una característica de la identidad y de las actitudes personales: se trata del conjunto de expectativas y creencias que se encuentran asociadas a modelos más o menos consensuados de lo que significa ser hombre o ser mujer en una cultura determinada.

Para el mismo autor, las personas elaboran y manifiestan su manera de comprender la cultura de género en función de estos dos planos; en cada uno de ellos se identifican determinados recursos culturales, que son los que van configurando la "construcción personal” de la cultura de género: cómo se aceptan las tradiciones heredadas de las generaciones anteriores (Rey \& Quintero, 2020), cómo se caracterizan los valores, cómo se construyen los 
discursos, etc. Esta propuesta de la noción de cultura de género "resulta muy útil para la creación de indicadores e instrumentos de medida y, muy especialmente, para la detección de actitudes y prácticas que puedan condicionar la construcción de una cultura de género en la escuela basada en la igualdad" (Rebollo et al., 2009, p. 529).

Es de esta forma como la construcción de la cultura de equidad dentro del marco de la educación requiere procesos de innovación que permitan la transversalización de la perspectiva de género. Esto último implica tener presente, entre otros, los enfoques de la violencia de género (en los que se promueva la igualdad y el respeto como principio y valor social de las prácticas educativas institucionales) y el diseño de estrategias que integren políticas, planes y proyectos educativos con igualdad de oportunidades; todo ello, mediado por un ejercicio imparcial del poder desde un enfoque ético, que redundaría en una equidad social efectiva.

La innovación educativa tiene tres campos claros de aplicación. El primero de ellos es la innovación en la gestión institucional, el segundo es la innovación curricular y el tercero la innovación didáctica. La innovación en la gestión institucional se encuentra asociada a las prácticas administrativas, a la toma de decisiones, a la dirección, planeación, organización, comunicación y evaluación. La innovación curricular vincula las prácticas diagnósticas, la definición de modelos y enfoques, y las prácticas de evaluación. La innovación didáctica se relaciona con las prácticas de intervención y mediación para la enseñanza, así como las de evaluación de aprendizaje (Macías, 2005).

Entender la innovación como un proceso dinámico es un reto del sistema educativo actual, ya que esto implica la combinación de varios elementos que no solo pretenden garantizar la formación de los estudiantes, sino también los procesos de calidad en la educación (Ortiz et al., 2015). Así, para Carbonell (2006), la innovación implica un proceso en el que se toman decisiones que permiten modificar actitudes, ideas, sesgos culturales, contenidos, modelos y prácticas pedagógicas. De esta manera, el concepto de innovación adquiere diferentes dimensiones; se trata, en esencia, de un cambio educativo que implica cambios estructurales (del sistema educativo), curriculares, profesionales, políticos y sociales (Weiss \& Rey, 2021). La innovación en la educación busca, 
entonces, cambios y reformas puntuales en la práctica educativa, proceso que se caracteriza por crear controversia debido a que en él está implícito el sentido de romper creencias y paradigmas; por tanto, implica un diálogo constante $\mathrm{y}$ abierto que genere un proceso reflexivo y que tenga un gran componente investigativo (Elliott, 2004).

Innovar requiere desarrollar una visión amplia y profunda de las cosas, donde los diferentes actores que intervienen puedan hacer sus aportes, construir desde diferentes miradas, realidades, para así trascender de lo cotidiano, lo rutinario, del aula de clase, de los métodos tradicionales, donde se dé espacio a la tecnología, a nuevos métodos para acercarnos a la realidad, al conocimiento, que permitan la reflexión, el autoanálisis y a partir de él, nuevas construcciones y dimensiones de la realidad que se nos presentan para generar procesos de innovación (Rincón \& Rodríguez, 2015), teniendo claro que uno de ellos es el enfoque ético en cuestiones de igualdad de género.

Como ciencia del deber ser, la ética puede aportar al análisis del tratamiento de las desigualdades y diferencias de género, pues aboga por los derechos y deberes de las personas, con lo cual contribuye al desarrollo humano. Este último está a favor de la equidad de género y contra la violencia, la invisibilización y la discriminación específicamente de la mujer (Gallego \& Bermúdez, 2010). De hecho, actualmente el principio de igualdad de género se consolida en todos los grupos sociales y las fuerzas armadas de algunos países lo incorporan como código moral de conducta (Moliner, 2018), por cuanto se entiende que los valores del soldado, si bien son los mismos del ciudadano, también se constituyen como una manifestación amplia y positiva de entrega por la defensa de la Patria, su bienestar y los principios que la fundamentan (Bachelet, 2006).

\section{El programa Atenea: una estrategia de innovación educativa}

Desde el año 2013, con la creación del Observatorio Militar para la Igualdad entre Hombres y Mujeres (a través de la Resolución n. ${ }^{\circ}$ 274), la EsMic inició un proceso de reestructuración y mejora de los programas académicos de los futuros oficiales del Ejército. En ese momento, se identificaron los prototipos que permeaban las tradiciones culturales y las prácticas de la sociedad y la familia colombiana, de forma tal que impedían o hacían al menos 
muy difícil la implementación de una política de equidad de género en el Ejército Nacional de Colombia, pues provocaban distorsiones de la percepción del rol de la mujer en la Fuerza. Para entonces, se continuaban las lógicas dicotómicas que separaban a los hombres y las mujeres en relación con la presunta capacidad de realizar tareas (Jaramillo, 2013).

En efecto, ciertos prejuicios de los estudiantes, generados por su cotidianidad antes de ingresar a la Esmic, fomentaban ciertos esquemas de rivalidad y mitos sobre el reconocimiento de logros, el trato discriminatorio y las desventajas profesionales para las mujeres dentro del Ejército. Camacho (2011) y Sandoval y Otálora (2015) plantean que se presentaban esquemas de rivalidad en los que los hombres, desde el momento en que las mujeres se empezaron a formar en la carrera de las armas, percibieron un trato inequitativo que favoreció el surgimiento de esquemas sociales de enfrentamiento, de igualación de fuerzas que lejos están de las propuestas de equidad.

Estos ambientes podían llegar a propiciar el dominio tanto del uno como del otro y no promovían la reestructuración, la mejora ni la transformación de las representaciones sociales en cuanto a los roles de hombres y mujeres. La falta de apropiación de una cultura de equidad de género llevó a que, en el caso de la Esmic, se entendiera como esencial el diseño de una "educación para toda la población de la Institución en la perspectiva de género orientado a lograr una cultura de inclusión" (Camacho, 2011, p. 88). En aquel entonces se evidenciaba que el rol de la mujer en el Ejército aún no lograba definir factores de gran importancia, por ejemplo, el valor de su participación en las operaciones militares.

Así las cosas, la Esmic creó en el año 2017 el Programa Atenea, estrategia educativa que apoya el Programa Educativo Institucional (PeI) en la promoción de la equidad, aunando los esfuerzos de los años anteriores y, en especial, evaluando la efectividad de las políticas implementadas y los cambios realizados en la Esmic. Así mismo, cubre la urgencia de tener políticas en cuanto equidad de género, con las que se fortalezcan los ideales sociales y culturales dentro del contexto del Ejército sobre la inclusión de la mujer militar como parte fundamental de la Fuerza. 
Atenea busca fortalecer la utilización de la perspectiva de género en la formación de los futuros oficiales del Ejército, lo cual no significa la eliminación de diferencias entre hombres y mujeres, sino permitir el aporte significativo de las personas a un objetivo institucional en relación con su condición y capacidades individuales.

De igual manera, Atenea opera mediante tres estrategias específicas (tabla 3): (1) ideas de investigación innovadoras, (2) metodologías en torno a la ciencia y (3) comunicación de resultados. De estas estrategias se desprenden las acciones que debe realizar el equipo del Observatorio Militar para la Igualdad entre Mujeres y Hombres en interacción con la comunidad académica. Ahora bien, al hablar de una cultura de respeto y equidad de género, el trabajo de la EsMIC se encamina a generar conocimiento y fomentar buenas prácticas entre sus estudiantes y el cuerpo docente, en un entorno actualizado y coherente no solo con las prácticas mundiales en cuanto a equidad de género, sino consecuente con el espíritu equitativo de la Constitución nacional y de un Estado social de derecho, de manera que se integran los postulados propios de la ciencia, la educación y, por supuesto, la mística y la tradición militar.

Las estrategias con las cuales opera Atenea generan procesos asociados a lo macro y mesocurricular, principalmente, por cuanto se promueve el conocimiento y el cambio cultural a partir de la generación y divulgación del conocimiento. Adicionalmente, el cambio progresivo de percepciones a estrategias que fomentan un currículo asociado a un mensaje positivo hacia la equidad de género. Precisamente, el trato igualitario, ausente de tratos discriminatorios en el proceso educativo, y el fomento del empoderamiento femenino en el ejercicio de su carrera profesional son elementos que ahora forman parte de la ética militar que se fomenta en la Esmic.

Un ejemplo de lo anterior son los esfuerzos del Programa Atenea para propiciar un ambiente en el que se reconozcan de manera efectiva los logros de la mujer militar en el Ejército Nacional, para lo cual promociona una red de divulgación que tiene como propósito incrementar este reconocimiento mediante un programa radial y capacitaciones a los estudiantes sobre el rol de la mujer militar. Esta estrategia ha logrado que la comunidad académica e institucional adquiera conciencia sobre las acciones que involucran a la mujer y 


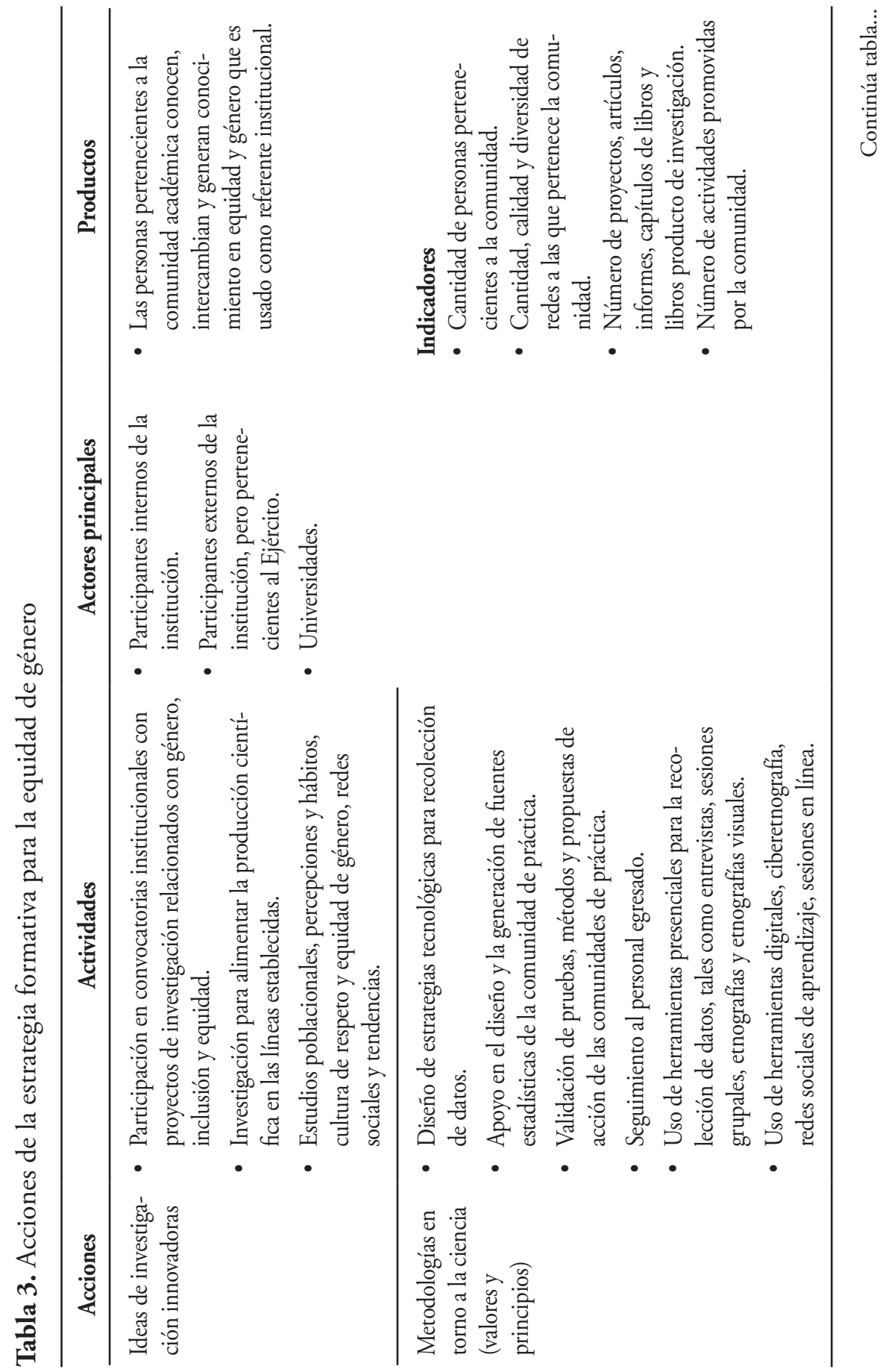




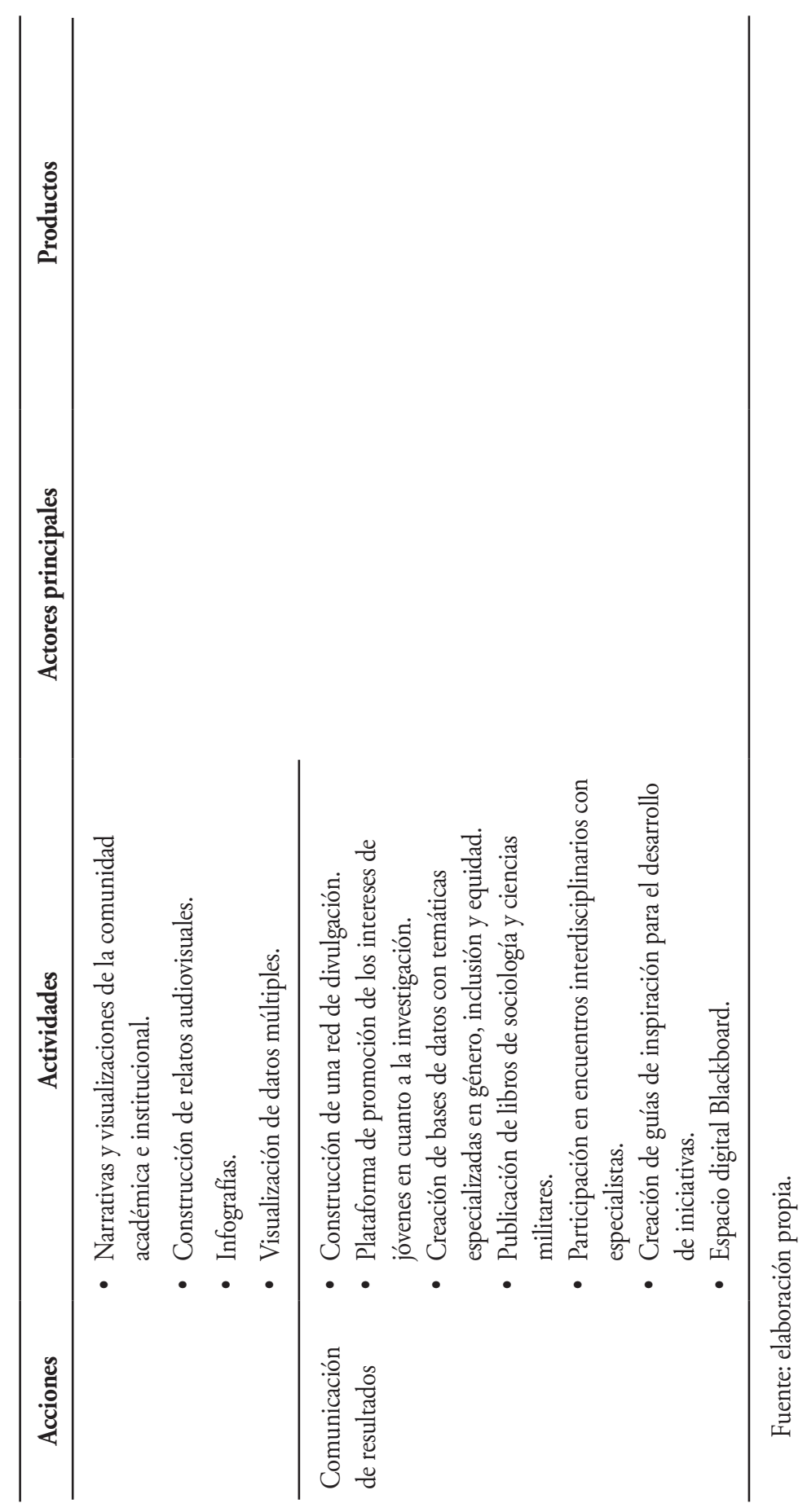


la hacen merecedora de incentivos propios de la institución, tales como comisiones al extranjero, anotaciones positivas en sus hojas de vida y distintivos por el ejercicio de sus principios y valores militares.

Adicionalmente, a partir del 2018, el Programa Atenea abandera su plan de acción en la estrategia de prevención y atención para la discriminación, el acoso y la agresión sexual. El programa capacita, entonces, a todos los actores de la comunidad educativa en cuanto a los lineamientos jurídicos, las condiciones psicológicas de estas conductas y los niveles de afectación tanto en lo personal como en lo institucional. De igual manera, se promueven los protocolos de intervención y las políticas institucionales a partir de cartillas que permiten orientar a la comunidad sobre las líneas de acción cuando se presente alguna dificultad al respecto.

El Programa Atenea plantea que tanto hombres como mujeres deben gozar de un trato no discriminatorio. En la Esmic, desde el momento en que se vinculan los estudiantes se tiene un cuidado especial para evitar el trato discriminatorio; de hecho, los currículos son construidos de manera tal que, sin importar el sexo, los cadetes cursan y aprueban sus materias tanto en lo académico como en lo militar desde una formación integral en competencias del ser, el saber, el hacer y el convivir. Esto hace que el Ejército Nacional reciba oficiales de grado subteniente, con capacidades de liderazgo y operativas iguales. Es de esta manera como la formación garantiza que una mujer y un hombre militar estén totalmente capacitados para ser efectivos en la misión que se les asigne.

Probablemente, las estrategias descritas anteriormente estén contribuyendo a un cambio cultural que se refleja en las percepciones de los cadetes, lo cual allana el camino hacia una ética militar en línea con las necesidades actuales. Asimismo, la información descrita en este documento permite evidenciar la necesidad de propuestas didácticas que expliciten la intencionalidad de los procesos de formación orientados a la equidad de género, es decir, una orientación microcurricular concreta.

Finalmente, a pesar de la implementación de todas estas iniciativas, en la Esmic no se había realizado una evaluación de las percepciones que tienen sus estudiantes sobre la equidad de género desde el ingreso a la EsMic hasta 
los niveles finales. El no contar con datos que muestren las realidades de la comunidad educativa hace que muchas de las acciones de mejora que se plantean para cubrir temas como la equidad entre hombres y mujeres no tengan el impacto deseado o no se visibilicen. En consecuencia, una de las formas para promover la cultura de equidad de género es fortalecer las propuestas de aprendizaje e investigación que se hagan al respecto en las escuelas de formación (Latorre \& Fernández-Osorio, 2018).

\section{Conclusiones y recomendaciones}

La promoción de la cultura de la igualdad en el ámbito militar es un proceso que se viene acentuando, y su práctica se evidencia desde el momento mismo de la incorporación de la mujer como cadete y estudiante en ciencia militar. La gestión educativa de la Esmic, a través del establecimiento de programas académicos y currículos, promueve el valor de la igualdad, ya que no disgrega la población por ninguna condición y permite que la formación militar sea la misma tanto para mujeres como para hombres durante los ocho semestres académicos.

Al hablar del reconocimiento de los logros de la mujer, es importante entender que en la educación se encuentra la clave para evitar las desigualdades sociales derivadas del género. De hecho, es mediante esta última que se puede llegar al descubrimiento y reconocimiento de las capacidades personales para el logro de una transformación como individuo que, a su vez, redunde en el beneficio de la sociedad.

El Programa Atenea, como estrategia de formación, provee las herramientas necesarias para fortalecer la igualdad entre hombres y mujeres, a partir de capacitaciones, espacios de comunicación y debate (como programas radiales y redes sociales) y el desarrollo de guías en torno al tema. Además, plantea acciones encaminadas a robustecer los procesos de investigación científica (grupos y proyectos de investigación) y su divulgación (libros, cartillas, redes y ponencias, entre otros), acciones que vinculan a la comunidad académica e institucional con las problemáticas y las opciones frente a los problemas de género. 


\section{El Ejército Nacional de Colombia y la Escuela Militar de Cadetes "General} José María Córdova” continúan su permanente labor en la construcción de una cultura de equidad de género y buscan establecerse como referentes en la implementación de estas estrategias en la región. Si bien el Programa Atenea, como estrategia de innovación educativa, ha logrado avances importantes para el fomento de la equidad de género, aún existen múltiples dimensiones susceptibles de mejora, en especial aquellas relacionadas con garantizar el reconocimiento de las capacidades individuales y el cumplimiento de la misión constitucional de la Fuerza en el marco de una ética militar en línea con las necesidades actuales.

\section{Referencias}

Abramo, L. (Ed.). (2006). Trabajo decente y equidad de género en América Latina. Organización Internacional del Trabajo.

Alcívar Zamora, N. X., \& Cedeño Barreto, M. (2012). La diversidad de género en el sistema de educación superior: Causa y efecto. Atlante Cuadernos de Educación y Desarrollo, 1-4. https://www.eumed.net/rev/atlante/2018/12/diversidad-genero-educacion.html

Apún Salinas, P. M. (2019). Equidad de género. https://www.zonaeconomica.com/paopunket/ equidad-genero

Ariza, M., \& De Oliveira, O. (1999). Inequidades de género y clase. Nueva Sociedad, (164), 70-81. http://investigacion.cephcis.unam.mx/generoyrsociales/wp-content/ uploads/2015/01/Inequidades-de-género-y-clase.-Algunas-consideraciones-analíticas.pdf

Arroyo Ortega, A., \& Álvarez, M. J. (2018). Violencias cotidianas: perspectivas situadas desde las experiencias de niñas y mujeres en el municipio de Medellín, Colombia. Sexualidad, Salud y Sociedad, (29), 123-146. https://doi.org/10.1590/1984-6487.sess.2018.29.06.a

Astelarra, J. (2005). Veinte años de politicas de igualdad. Cátedra.

Avelar Giannini, R., De Moraes, O. C. R., \& Díaz, M. (2018). Género, justicia y seguridad en Brasil y en Colombia: ¿Cómo prevenir y tratar la violencia contra las mujeres? https:// igarape.org.br/wp-content/uploads/2018/05/Género-justicia-y-seguridad-en-Brasil-y-enColombia.pdf

Bachelet, J. (2006). Por una ética de la profesión militar para vencer la violencia. Editions Vuibert.

Barredo Ibáñez, D., Cevallos, M. del C., \& Zurbano-Berenguer, B. (2014). El concepto de violencia de género en el imaginario latinoamericano: Estudio sobre los universitarios quiteños. En Libro de Actas del II Congreso Internacional de Comunicación y Género (pp. 462-472). Facultad de Comunicación de Sevilla. https://idus.us.es/xmlui/ handle/11441/31795 
Betancur Jiménez, G. E. (2016). La ética y la moral: Paradojas del ser humano. CES Psicología, 9(1), 109-121.

Camacho, K. (2013). Análisis de la integración de la perspectiva de género en las agendas y politicas digitales de Latinoamérica y el Caribe. CEPAL. https://repositorio.cepal.org/ handle/11362/4080

Camacho Zambrano, C. M. (2011). Políticas de equidad de género en las Fuerzas Armadas. Impactos en la cultura institucional militar: el caso de la incorporación de cadetes femeninas en la ESMIC. Revista Cientifica General José Maria Córdova, 9(9), 69-94. https://doi.org/10.21830/19006586.246

Carbonell Sebarroja, J. (2006). La aventura de innovar: el cambio en la escuela. Morata.

Castillo-Acobo, R. Y., \& Choqque-Soto, S. R. (2018). Percepción de violencia y sexismo en estudiantes universitarios. Entorno, (66), 51-66. http://biblioteca.utec.edu.sv/sitios/entorno/ index.php/entorno/article/view/550

Chant, S. H., Craske, N., \& Stellino, B. M. (2007). Género en Latinoamérica. Centro de Investigaciones y Estudios Superiores en Antropología Social.

Comisión Económica para América Latina y el Caribe [CEPAL]. (2019). Planes de igualdad de género en América Latina y el Caribe. Mapas de ruta para el desarrollo. CEPAL.

Cone, C. M. (2018). Child sexploitation: A study of machismo and the commercial sexual exploitation of children in Latin America. http://thesis.honors.olemiss.edu/1151/

Constitución Política de Colombia. (1991). Congreso de la República. http://www.corteconstitucional.gov.co/inicio/Constitucion politica de Colombia.pdf

Cota Olmos, A. (2002). La importancia de los valores en el desarrollo humano de la organización [Tesis de doctorado, Universidad Autónoma de Nuevo León]. Repositorio institucional. http://eprints.uanl.mx/1001/1/1020147482.PDF

Daros, W. R. (2014). La mujer posmoderna y el machismo. Franciscanum, 56(162), 107-129. http://antroposmoderno.com/antro-articulo.php?id_articulo=4

Eggleton, M. (2018). No so macho, macho man: Effects of machismo culture on women in Latin America. Ponencia presentada en la COLA Research and Creativity Conference. https://mds.marshall.edu/colaconf/2018/day2/43

Elliott, J. (2004). The struggle to redefine the relationship between "knowledge" and "action" in the academy. Educar, (34), 11-24. https://ddd.uab.cat/record/1165

Felitti, K., \& Rizzotti, A. (2016). El "machismo latinoamericano" y sus derivas en la educación internacional: Reflexiones de estudiantes estadounidenses en Buenos Aires. Magis: Revista Internacional de Investigación en Educación, 9(18), 13-28. https://ialnet. unirioja.es/servlet/articulo? codigo $=5762697$

Fernández-Osorio, A., Latorre Rojas, E., \& Mayorga, N. (2018). The 2018 Colombian Military Academy dataset: A sociological study of population. Revista Cientifica General José María Córdova, 16(23), 147-162. https://doi.org/10.21830/19006586.345

Gallego, Y. A., \& Bermúdez, D. P. (2010). Ética y género: una reflexión necesaria. Universidad y Sociedad, 2(3). https://rus.ucf.edu.cu/index.php/rus/article/view/80 
Galvis-Aponte, L. A. (2010). Diferenciales salariales por género y región en Colombia: Una aproximación con regresión por cuantiles [Documentos de Trabajo sobre Economía Regional y Urbana, 131]. Banco de la República de Colombia. Recuperado de http:// repositorio.banrep.gov.co/handle/20.500.12134/3024

García, L. M., \& Martija, A. (2006). ¿ Qué entendemos por innovación educativa? A propósito del desarrollo curricular. Perspectiva Educacional, Formación de Profesores, (47), 13-31.

Gómez, R. J. G. (2005). Innovación, cultura y poder en las instituciones educativas. La complejidad en el cambio de educación. Educar, (35), 11-27.

González-González, C., García-Holgado, A., García-Peñalvo, F., \& Mena, J. (2018). Educando para la igualdad en la universidad: Experiencias de innovación docente en la enseñanza de la informática. https://repositorio.grial.eu/bitstream/grial/1326/1/educando-para-laigualdad-en-la-universidad.pdf

González, K., Mortigo, A., \& Berdugo, N. (2014). La configuración de perfiles profesionales en la educación superior y sus implicaciones en el currículo. Revista Cientifica General José María Córdova, 12(14), 165-182. https://doi.org/10.21830/19006586.62

Guarnizo-Herreño, C. C., \& Agudelo, C. (2008). Equidad de género en el acceso a los servicios de salud en Colombia. Revista de Salud Pública, (10), 44-57. https://doi.org/10.1590/ S0124-00642008000600005

Heise, L. (1998). Violence against women: An integrated, ecological framework. Violence Against Women, 4(3), 262-290. https://doi.org/10.1177/1077801298004003002

Jaramillo Ruiz, F. (2013). Poder, género y democracia. De la dominación a la igualdad de género. Revista Cientifica General José María Córdova, 11(12), 107-125. https://doi. org/10.21830/19006586.189

Knippers Black, J. (2018). Latin America its problems and its promise. London: Routledge. https://doi.org/10.4324/9780429495069

Latorre Rojas, E., \& Fernández-Osorio, A. (2018). Innovación educativa para el fomento de la equidad de género en las Fuerzas Militares. En A. Fernández-Osorio \& E. LatorreRojas (eds.), La construcción del rol de la mujer militar (pp. 141-160). Sello Editorial ESMIC.

Leal, J. O. G., \& Useche, M. C. (2009). Educación, ética y cultura: Una mirada desde Paulo Freire. Telos: Revista de Estudios Interdisciplinarios en Ciencias Sociales, 11(2), 182-193.

Londońo Toro, B., Rubio, L. O., \& Castro, J. F. (2017). La violencia de género no tiene fronteras. Estudio comparativo de las normativas colombiana y española en materia de violencia de género (2004-2014). Revista Derecho del Estado, (38), 127-154. https:// doi.org/10.18601/01229893.n38.05

Macías, A. B. (2005). Una conceptualización comprehensiva de la innovación educativa. Innovación Educativa, 5(28), 19-31.

Mcllwaine, C. (2010). Migrant machismos: exploring gender ideologies and practices among Latin American migrants in London from a multi-scalar perspective. Gender, Place \& Culture, 17(3), 281-300. https://doi.org/10.1080/09663691003737579 
Meertens, D. (2017). La dimensión de género en el desplazamiento interno: Respuestas institucionales en el caso colombiano. Deusto Journal of Human Rights, O(9), 41. https://doi. org/10.18543/aahdh-0-2011pp41-52

Miranda-Novoa, M. (2012). Diferencia entre la perspectiva de género y la ideología de género. Dikaion, 21(2), 337-356. http://www.scielo.org.co/pdf/dika/v21n2/v21n2a02.pdf

Moliner, J. A. (2018a). ¿Por qué es importante la ética militar? Revista Española de Defensa, (30-31). https://www.defensa.gob.es/Galerias/gabinete/red/2018/red-353-etica-militar. pdf

Moliner, J. A. (2018b). ¿Qué es la ética militar? Boletín IEEE, (11), 615-643.

Montoya Ruiz, A. M. (2009). Recorrido por las políticas públicas de equidad de género en Colombia y aproximación a la experiencia de participación femenina con miras a la construcción de escenarios locales. Estudios de Derecho, 66(147), 303-319. http://aprendeenlinea.udea.edu.co/revistas/index.php/red/article/view/2418

Moreno, M. G. (1995). Investigación e innovación educativa. Revista la Tarea, (7).

Muñoz Sánchez, P., \& Iniesta Martínez, A. (2017). La violencia de género en jóvenes adolescentes desde los estereotipos de las relaciones de pareja. Estudio de caso en Colombia y en España. International Journal of Developmental and Educational Psychology, 2(1), 169-178. https://doi.org/10.17060/ijodaep.2017.n1.v2.929

Olson. J. (1992). Understanding teaching beyond expertise. Millón Kcynes / Open University Press.

Ordorika, I. (2015). Equidad de género en la educación superior. Revista de la Educación Superior, 44(174), 7-17.

Organización de Estados Interamericanos [OEA]. (s. f.). Desarrollo de innovaciones en la educación y atención de niños y niñas de 0 a 6 años. Plan de Formación "Innovaciones en educación y atención infantil en programas formales y no formales".

Organización de las Naciones Unidas [ONU]. (2016). Agenda 2030 y los objetivos de desarrollo sostenible. Una oportunidad para América Latina y el Caribe. www.un.org/sustainabledevelopment/es

Organización Mundial de la Salud [OMS]. (2002). Informe mundial sobre la violencia y la salud. https://www.who.int/violence_injury_prevention/violence/world_report/es/ summary_es.pdf

Organización Mundial de la Salud [OMS]. (2013). Estudio multipais de la OMS sobre salud de la mujer y violencia doméstica contra la mujer. OMS. https://www.who.int/gender/ violence/who_multicountry_study/summary_report/chapter1/es/

Organización para la Cooperación y el Desarrollo Económicos [OECD]. (2017). The pursuit of gender equality. OECD. https://doi.org/10.1787/9789264281318-en

Ortiz Ocaña, A., Sánchez Buitrago, J., \& Sánchez Fontalvo, I. (2015). Los modelos pedagógicos desde una dimensión psicológica-espiritual. Revista Cientifica General José María Córdova, 13(15), 183-194. https://doi.org/10.21830/19006586.22

Otálvaro Marín, B., Ceballos Molano, R., Bonilla-Mejía, L. M., \& Gómez, C. W. (2018). Violencias de género: un conflicto a transformar en la educación superior en Colombia. 
Entorno, (66), 136-147. http://biblioteca.utec.edu.sv/sitios/entorno/index.php/entorno/ article/view/557

Otero García, M. A., \& Ibarra Melo, M. E. (2017). Behind the numbers of violence against women in Colombia. Sociedad y Economía, (32), 41-64. http://www.scielo.org.co/ scielo.php?pid=S1657-63572017000100041\&script=sci_abstract\&tlng=en

Pardo, Y., Weisfeld, C., Hill, E., \& Slatcher, R. B. (2013). Machismo and marital satisfaction in Mexican American couples. Journal of Cross-Cultural Psychology, 44(2), 299-315. https://doi.org/10.1177/0022022112443854

Piquer, M. P. (2012). La cultura de género en la actualidad: actitudes del colectivo adolescente hacia la igualdad. Tendencias Pedagógicas, (19), 189-210.

Plan Nacional de Igualdad y Equidad de Género [PLANEG]. (s. f.). Ministerio de la Mujer de Chile.

Rebollo, M., García-Pérez, R., Piedra, J., \& Vega, L. (2011). Diagnóstico de la cultura de género: actitudes del profesorado hacia la igualdad. Revista de Educación, (355), 521-546.

Rey Pinto, E. M. (2021). En las aguas de la distinción: Imaginarios sobre el prestigio en la Armada Nacional de Colombia. Revista Cientifica General José María Córdova, 19(35), 625-642. http://dx.doi.org/10.21830/19006586.654

Rey Pinto, E. M., \& Quintero Toro, C. (2020). Seguridad y cuidado: una mirada a la Mara Salvatrucha en el Triángulo Norte. En E. Rey Pinto \& D. Rodríguez Samora (eds.), Crimen Organizado Transnacional: Fronteras y actores en el hemisferio (pp. 161-184). Editorial Planeta.

Reyes, G. E. (2012). Centros urbanos de América Latina 1997, 2006: Disparidades salariales según género y crecimiento económico. Revista de Ciencias Sociales, O(131-132), 147-168. https://doi.org/10.15517/rcs.v0i131-132.3899

Rincón Cardona, C. A., \& Rodríguez Hurtado, C. P. (2015). Hacia la innovación educativa: Beneficios, desafíos y actores [Trabajo de grado en Gerencia Educativa, Universidad de Manizales]. Repositorio institucional. http://repositorio.ucm.edu.co:8080/jspui/ bitstream/handle/10839/1200/Carlos\%20Alberto\%20Rincon\%20Cardona.pdf?sequence $=1$ \&isAllowed $=y$

Rodríguez, M. (2015). Culturas organizacionales éticas. Revista de Antropología y Sociología: Virajes, 17(1), 107-134.

Rojas Rojas, S. (2018). ¿Se puede hablar de equidad en el sector educativo colombiano? Revista Cientifica General José María Córdova, 16(23), 125-143. https://doi. org/10.21830/19006586.286

Ronconi, L. (2018). Derecho a la educación e igualdad como no sometimiento. Universidad Externado de Colombia. http://www.dijuris.com/es/libro/derecho-a-la-educacion-e-igualdad-como-no-sostenimiento_32671

Ruiz-Gutiérrez, J. M., \& Santana-Vega, L. E. (2018). Elección de carrera y género. Revista Electrónica de Investigación y Docencia (REID), (19), https://doi.org/10.17561/reid. v0i19.3470 
130 Volumen III. Ética militar, equidad de género y construcción de paz.

Sandoval, L. \& Otálora, M. (2015). Desarrollo corporal y liderazgo en el proceso de formación militar. Revista Cientifica General José María Córdova, 13(16), 33-53. https://doi. org/10.21830/19006586.30

Suárez Díaz, D., Liz, A. del P., \& Parra Moreno, C. (2015). Construyendo tejido social desde la Escuela Nueva en Colombia. Un estudio de caso. Revista Cientifica General José María Córdova, 13(15), 195-229. https://doi.org/10.21830/19006586.23

Vargas Manrique, P. (2016). Una educación desde la otredad. Revista Cientifica General José María Córdova, 14(17), 199-222. https://doi.org/10.21830/19006586.9

Weiss, C., \& Rey Pinto, E. M. (2020). Twenty years after UNSCR 1325: Equal access to military education in the Western Hemisphere? Estudios en Seguridad y Defensa, 15(30), 303-325. https://doi.org/10.25062/1900-8325.280 